\title{
Dystocia Caused By Sacrococcygeal Teratoma: A Case Report
}

\author{
TR LAILA
}

\begin{abstract}
Summary:
A 23-year-old pregnant mother presented with labor pain for 14 hours with delivery of part of a baby with the exception of right leg. Single ultrasonography (USG) done at 34 weeks of gestation showed an anechoic area measuring $8 \mathrm{~cm} \times 6 \mathrm{~cm}$ surrounded by a thin rim. The patient was put under general anesthesia $(G A)$ and the right leg of the baby was drawn out of the uterus. A soft tissue mass partly cystic in nature, connected with the perineal region of the baby, prevented the complete
\end{abstract}

\section{Introduction:}

Sacrococcygeal teratoma (SCT) is the most common congenital tumor in the neonate reported in approximately $1 / 35,000$ to $1 / 40,000$ live birth. ${ }^{1}$ In the modern era, the first large series of infants and children with SCT was reported by Gross et al in 1951.2 SCT have tissues derived from ectoderm, mesoderm, and endoderm. ${ }^{\mathbf{1}}$ Although their embryonic origin is still uncertain, they are believed to arise early in gestation (at around the late second or early third weeks of pregnancy) from the totipotential cells of Hensen's node, a remnant of the primitive streak in the coccygeal region. ${ }^{3-5}$ The sacrococcygeal region is the most common location. It may be classified as benign (mature), immature (composed of embryonic elements) and malignant. Though described as early as the $19^{\text {th }}$ century, it was not until the advent of antenatal ultrasonography (USG) that SCT were diagnosed in utero. ${ }^{6}$ From obstetric point of view, fetuses with this malformation may have associated morbidity and mortality related to prematurity, dystocia, traumatic delivery and intra tumoral hemorrhage. In addition, mother with this complicated pregnancy may have morbidity like

Address for Correspondence: Dr. Tarafdar Runa Laila, FCPS (Obs \& Gyne), MS (Obs \& Gyne), Assistant Professor, Department of Obstetrics \& Gynecology, Sir Salimullah Medical College, Dhaka, Bangladesh

Received: 26 September, 2007

Accepted: 14 January, 2008 delivery. After decompressing the mass, complete delivery was possible. But exploration of the uterus showed rupture in the left lateral wall. Laparotomy with repair of the uterus was done. Excision of the soft tissue mass of the baby was done one day after delivery and histology of the mass showed mature sacrococcygeal teratoma. Postoperative recovery of both the mother and the baby was good.

(J Bangladesh Coll Phys Surg 2009; 27: 169-172)

polyhydramnios, premature labor, and dystocia. Here a case of undiagnosed SCT is presented which becomes an obstetrician's nightmare.

\section{Case report}

A 23 year old Non Government Organization worker of middle class family hailing from Hazigang, Chandpur was admitted in a private clinic of Comilla with the complaints of labor pain for 14 hours with delivery of the whole body of a baby with the exception of right leg. Detailed history revealed that she was a $2^{\text {nd }}$ gravida; her first baby was delivered at home about 4 years back without any complication. She did not give history of any medical disease. During her present pregnancy she had a single antenatal check up at 34 weeks of gestation by a local MBBS doctor. She had only one ultrasonogram at 34 weeks of pregnancy, which showed a single fetus with cephalic presentation. In addition, the sonologist mentioned about a huge anechoic area measuring 8 $\mathrm{cm} \times 6 \mathrm{~cm}$ surrounded by a thin rim. The patient was informed about the presence of a fluid filled sac inside her uterus, which was not seriously taken by her or her guardian. Also she was not advised for hospital delivery. She had no other investigations done during her pregnancy.

Five days past the expected date of delivery there was spontaneous onset of labor pain at home. She was attended by an untrained birth attendant. About 7 hours after the onset of labor pain she delivered a 
baby by cephalic presentation. But arrest of the trunk occurred at the level of the umbilicus .The birth attendant failed to deliver rest of the body. Then a nurse was called at home who after augmentation of the labor by oxytocin was able to deliver the left leg. But delivery of the right leg was not possible. Then she was first taken to a clinic in Chandpur from where she was referred to a clinic in Comilla.

On admission in the clinic of Comilla her pulse was 100/minute, BP: $90 / 60 \mathrm{~mm}$ of $\mathrm{Hg}$, height of the uterus was about 32 weeks, soft, but no fetal parts were found or no fetal heart sound was audible. Pelvic examination revealed that the baby was taking respiration. There was edema of the left leg and right leg was inside the uterine cavity. A big soft tissue mass obstructing the os was found. Catheterization was done which showed hematuria. Patient was put under general anesthesia. Under all aseptic precaution a hand was inserted inside the uterus along the sacral hollow. The uterus was found to be filled up with the soft tissue mass. However the right leg was drawn out of the uterus. But as the mass was attached with the perineal region of the baby, to dislodge the baby from the uterus, a puncture was made on a cystic part of the tumor with the release of large amount of fluid. Then the tumor was delivered. The tumor was about $30 \mathrm{~cm}$ $\mathrm{x} 20 \mathrm{~cm}$ in size arising from the perineum as well as connected with the groin (Fig-1). After delivery of the baby placenta was delivered and exploration of the uterine cavity showed rupture along the left lateral wall. Then laparotomy was done. The tear was a linear one involving the left wall vertically like

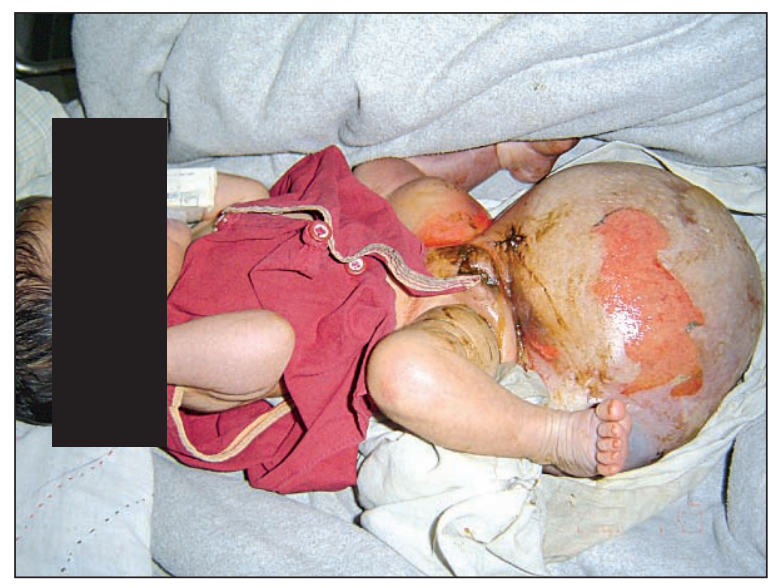

Fig-1: Baby with the tumor before operation. vertical extension of cesarean incision but without involvement of the uterine artery.

The tear was repaired. Abdomen was closed in layers after toileting and keeping a drain in the peritoneal cavity. Three units of blood were transfused postoperatively. Now comes the end of the hazardous intrapartum period of that lady.

Immediately after birth the baby was seen by a pediatric surgeon who provisionally diagnosed the tumor as a SCT and advised for excision. One day after birth, excision of the tumor was done under general anesthesia. The tumor was partly cystic and partly solid. Tissue was sent for histopathology, which showed features of mature cystic teratoma having tissue derived from all three germ layers. Apparently no other anomaly was seen in that baby.

The postoperative recovery of both the mother and the baby was uneventful. However edema with restricted movement of the left leg of the baby persisted during her hospital stay (Fig-2). They were discharged from the hospital on $10^{\text {th }}$ postoperative day.

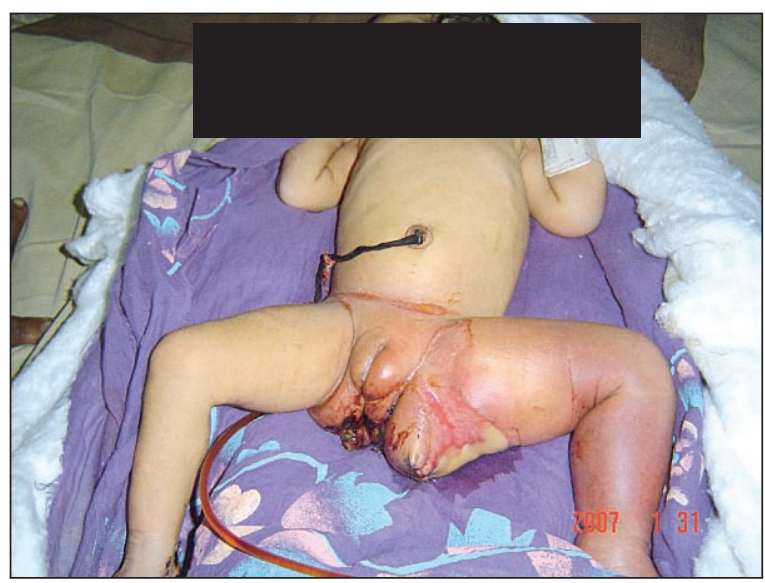

Fig-2: Appearance of the baby after operation.

\section{Discussion}

The perinatal management of SCT requires an interdisciplinary liaison between obstetrician, neonatologist and pediatric surgeon. But in this case the mother as well as her newborn was very unfortunate. The prime reason for this is that in our country pregnant mothers are still very much neglected. The rate of antenatal care is $52 \%$. She received antenatal checkup once in her pregnancy 
period. She had a USG done at 34 weeks where though the sonologist mentioned the presence of an anechoic area together with the fetus, site of the mass was not mentioned. Neither the sonologist nor the obstetrician gave importance to it. The consequence of which was the development of obstructed labor and its complications. If the case had been referred to a senior obstetrician the complications which developed during labor, might not occur.

It is recommended that all fetuses diagnosed with SCT undergo detailed sonographic evaluation to confirm the diagnosis, type of SCT, rule out associated anomalies and the presence or absence of hydrops fetalis. ${ }^{6}$ Sonographic evaluation of placenta is also important. Bond et al postulated that the tumor acts as an arteriovenous fistula resulting in high output cardiac failure with placentomegaly and nonimmune hydrops. ${ }^{7}$ The association of hydrops and SCT is usually fatal prior to 30 weeks gestation. But in this case as the tumor was partly cystic and partly solid, the baby did not develop hydrops.

In most instances the abnormal size of the uterus leads to a fetal diagnosis of SCT by USG. In this case according to the mother's statement neither the abdomen was hugely enlarged nor she had much mechanical discomfort. The reason may be the baby was a dysmature one weighing $2 \mathrm{~kg}$ and the tumor was not totally solid.

Majority of the sacrococcygeal teratoma cases present between the $22^{\text {nd }}$ and $34^{\text {th }}$ week of gestation. In this case SCT was diagnosed at 34 week though she had no other USG done beforehand. Most are benign, resectable after birth without significant morbidity and rarely associated with other congenital anomalies. In this case the tumor was also resectable and after resection the baby did not develop any complication.

The size of a SCT determines the mode of delivery. Nonvascular tumor and those less than $10 \mathrm{~cm}$ in diameter may be delivered vaginally. ${ }^{8}$ However Gross et al recommended cesarean delivery in all fetuses with SCT of more than $5 \mathrm{~cm}$ diameter to minimize the risk of rupture and hemorrage. ${ }^{9}$ Tumor size has been more than $10 \mathrm{~cm}$ in almost all reported cases with difficult deliveries. ${ }^{10}$
The diagnosis of SCT on routine USG is associated with a greater than expected incidence of prenatal and perinatal complications. ${ }^{11}$ Close antenatal follow up is needed to optimize patient counseling and treatment in the presence of a completely solid tumor and the onset of polyhydramnios. A poor outcome is usually correlated with placentomegaly, cardiomegaly or nonimmune hydrops fetalis. ${ }^{11}$

Volume reduction amniocentesis and tocolysis may be required to treat symptomatic polyhydramnios and prevent preterm delivery. The high output cardiac failure is related to "vascular steal" from the high blood flow through the tumor. But if the tumor is cystic due to less blood supply hydrops rarely develop. Baby in this case also did not develop hydrops, as the tumor was partly cystic and partly solid. Fetal hydrops and placentomegaly may also jeopardize maternal health through the 'maternal mirror' syndrome in which the mother's condition mirrors that of the sick fetus. Other risks in SCT are preterm labor and premature delivery due to polyhydramnios and /or the mass of the tumor. In this case the patient had spontaneous onset of labor. Here though the mass was a big one but it was partly cystic and the baby was a dysmature one. So there was no evidence of hydrops. In SCT there is chance of fetal anemia or fetal exsanguinations caused by spontaneous bleeding of the tumor or tumor rupture during delivery. It is also recommended to do cesarean delivery to avoid tumor rupture or dystocia. As this case was diagnosed after onset of labor with delivery of half of the trunk, there was no scope of cesarean section, the outcome of which was very troublesome intranatal period, which ultimately led to rupture uterus.

In developed country even fetal surgery is done for management of SCT during antenatal period. We are not yet upto that stage. What we want is that every pregnant mother should receive proper antenatal care, regular ultrasonographic monitoring and also the specialist's care where it is needed.

\section{Conclusion:}

This woman suffered a lot due to lack of proper antenatal as well as intranatal care. Our obstetric service should be improved to give antenatal care to every pregnant woman, so that high risk cases can be 
identified and referred to specialized hospital. In this way we can avoid this type of obstetric complication.

\section{References:}

1. Winderl LM, Silverman RK. Prenatal Identification of a completely cystic internal sacrococcygeal teratoma (type IV). Ultrasound Obstet Gynecol 1997; 9:425-428.

2. Gross RE, Clatworthy HW, Meeker IA. Sacrococcygeal teratoma in infants and children: report of 40 cases. Surg Gynecol Obstet 1951; 92:341-352.

3. Izant RJ, Filston HC. Sacrococcygeal teratomas: analysis of 43 cases. Am J Surg 1975; 130:617-621.

4. Ein SH Adeyemi SD, Mancer K. Benign sacrococcygeal teratoma in infants and children: a 25-year review. Ann Surg 1980; 191:382-384.

5. Moazam F, Talbert JL. Congenital anorectal malformations: harbingers of sacrococcygeal teratomas. Arch Surg 1985; 120:856-859.
6. Callen PW. Ultrasonography in Obstetrics and Gynecology, 3rd ed. W.B. Saunders Company.1994: 543-545.

7. Bond SJ, Harrison MR, Schmidt KG. Death due to highoutput cardiac failure in fetal sacrococcygeal teratoma. J Pediatr Surg 1990; 25:1287-1291.

8. Kum CK, Wong YC, Prabhakaran K. Management of fetal sacrococcygeal teratoma. Ann Acad Med 1993; 22:377-380.

9. Gross SJ, Benzie RJ, Sermer M, et al. Sacrococcygeal teratoma: prenatal diagnosis and management. Am J Obstet Gynecol 1987; 156:393-396.

10. Altman RP, Randolph JG, Lilly JR. Sacrococcygeal teratoma. American Academy of Pediatrics Surgical Section survey.1973.J Pediatr Surg 1974; 9:389-398.

11. Holterman AX, Filiatrault D, Lallier M, et al. The natural history of sacrococcygeal teratomas diagnosed through routine obstetric sonogram: a single institution experience. J Pediatr Surg 1998; 33:899-903. 